\title{
CONGENITALATROPHODERMA OF PASINI AND PIERINI WITH VITILIGO: A
}

\section{RARE CASE REPORT}

Kanishk Utkarsh Kaushik ${ }^{1}$, Anil Kumar Gupta², Kankambari Pandey ${ }^{3}$

\section{HOW TO CITE THIS ARTICLE:}

Kanishk Utkarsh Kaushik, Anil Kumar Gupta, Kankambari Pandey. "Congenitalatrophoderma of Pasini and Pierini with Vitiligo: A Rare Case Report". Journal of Evolution of Medical and Dental Sciences 2014; Vol. 3, Issue 71, December 18; Page: 15203-15208, DOI: 10.14260/jemds/2014/4045

INTRODUCTION: Idiopathic atrophoderma of pasini and pierini is a form of dermal atrophy that manifests as single or multiple sharply demarcated hyper pigmented, non-indurated patches.

The patches are marked by slight depression of the skin with an abrupt edge, usually on back of adolescent and young adults, the lesion may be discrete or confluent. The affected skin appears thinned and discolored but consistency and feel of the affected skin remains normal.

HISTORY: In 1923 pasini( ${ }^{(1)}$ described a case of pigmentary atrophoderma that was both clinically and histologically unique from any known atrophy including localized scleroderma.

In 1936 Argentina, pierini, vivoli(2) extensively studied and defined the condition and its extensive link to morphea.

In 1958 the disorder was first introduced into American dermatology literature by canizares et al.(3) Since then reports of co-occurrence of morphea and occasionally lichen sclerosus et atrophicus with atrophoderma of pasini and pierini suggest a close relationship between the two.

In 2000 yokoyama et al reported that skin glycosaminoglycans extracted from atophoderma are different from those of typical morphea lesions.

EPIDEMIOLOGY: The exact incidence of idiopathic atrophoderma of pasini and pierini is not known. The small number of case reports represents its asymptomatic nature. It is more frequently reported from Europe and north America as compared to Asia:

- It is more common in whites and rarely seen in blacks or Asians.

- It is more frequently encountered in women than men with a ratio of 6:1.

- It usually begins insidiously in individuals during second or third decade.

- Only two cases of congenital atrophoderma have been reported so far.(4)(5)

CASE REPORT: A 17 year old female presented with innumerable round and oval lesions of varying size, mostly $<1.5 \mathrm{~cm}$. The lesions were present since her birth.

The lesions were slightly depressed below the level of the skin and were present predominantly on trunk, abdomen with a few lesions also present on her back.

New lesion continued to appear for next 2 to 3 years, after which they persisted unchanged for next 15 years only increasing with the size of the body. 


\section{CASE REPORT}

FIGURE 1: SHOWS PITS OF CONGENITAL ATROPHODERMA PRESENT SINCE BIRTH.

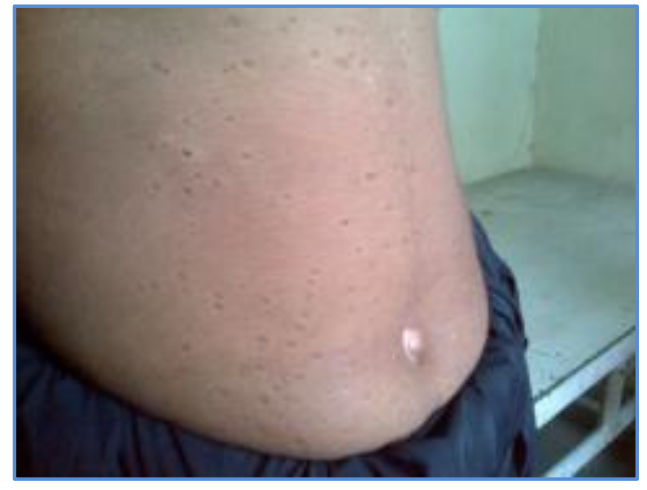

\section{FIGURE 1}

Within next 2 weeks of their appearance lesions became hyper pigmented, appearing slate brown to grey in color. Old lesions slowly enlarged to give skin moth eaten appearance, transformation to generalized morphea was not observed.

- There was no history suggestive of systemic involvement.

- There was no history of similar complaint in any family member.

- The same patient also started developing vitiligo at the age of 16 years which started from axilla and gradually progressed to involve back, neck and chest.

- No history of vitiligo was present in any family member.

- History of burn, trauma, and contact depigmentation was excluded.

FIGURE 2: SHOWS LESIONS OF CONGENITAL ATROPHODERMA ALONG WITH VILTILIGO INVOLVING THE UMBILICAL AREA.

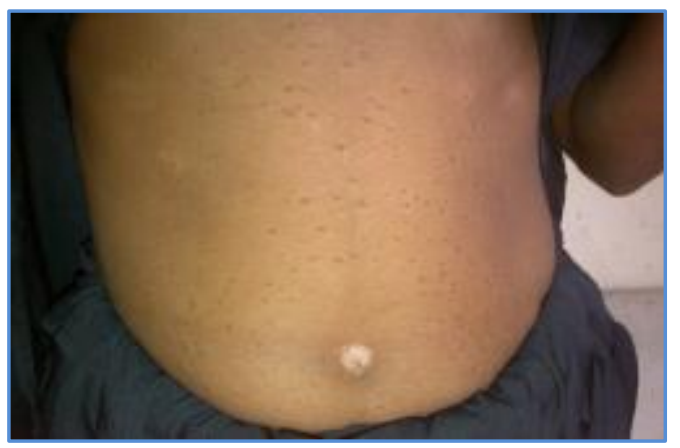

\section{FIGURE 2}

\section{DERMATOLOGICAL EXAMINATION:}

- For atrophoderma -lesions were multiple, round, and ovoid, varying in size to few centimeters.

- A predilection for abdomen was observed.

- The face hands and feet were relatively spared. 


\section{CASE REPORT}

- Distribution was not bilaterally symmetrical and lesions were hyperpigmented.(6)

- The lesions were asymptomatic and lacked inflammation.

- The skin was depressed below the level of surrounding skin in the lesions, ranging in depth from 1 to $8 \mathrm{~mm}$.

- Vitiliginous depigmentation was observed on chest, neck and back.

FIGURE 3: SHOWS VITILIGINOUS DEPIGMENTATION NEAR RIGHT SUPRAMAMMARY AREA ALONG WITH THE LESIONS OF CONGENITAL ATROPHODERMA, THE SHARP BORDER COULD BE NOTED.

Oral and genital mucosa, nails and hair were in normal limits.

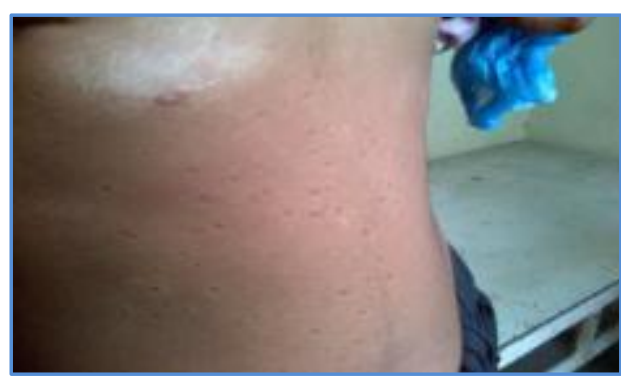

\section{FIGURE 3}

\section{INVESTIGATIONS:}

- Complete blood count, liver and renal function test, urine and stool were in normal limits.

- Anti borrelia burgdorferi antibodies were not found.

- $\quad$ Thyroid profile was with in normal limits.(7)

HISTOPATHOLOGY: From abdomen - showed epidermis and dermis, epidermis showed stratified squamous epithelium and orthokeratotic type of hyperkeratosis, melanin was increased in basal layer.

Dermis shows thinning with presence of few adenexal glands; mild perivascular inflammatory infiltrate consisting of lymphocytes and histiocytes was present.

The sweat glands, pilosebaceous units and appendages were unremarkable.

FIGURE 4: SHOWS STRATIFIED SQUAMOUS EPITHELIUM WITH HYPERKERATOSIS AND INCREASED MELANIN IN BASAL CELL LAYER.

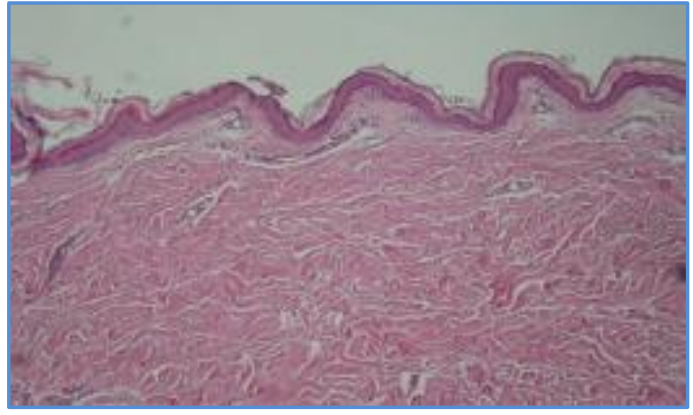

FIGURE 4 


\section{CASE REPORT}

- Collagen sclerosis was absent ruling out morphea.

- From vitiligo lesion - biopsy showed absence of melanin granules and melanocytes in the basal layer.

- A dermal lymphocytic infiltrate was present hence confirming the diagnosis of vitiligo.

TREATMENT: Since the patient was not concerned for atrophoderma we treated her with methylprednisolone pulse therapy as per $1 \mathrm{mg} / \mathrm{kg}$ body weight, the pulse therapy was given on weekly basis (i.e on two consecutive days of the week every week till 6 months then tapered after the vitiligo was controlled) along with, tacrolimus $0.1 \%$ ointment, and PUVA sol for vitiligo and explained prognosis for atrophoderma.

DISCUSSION: Congenital atrophoderma of pesini pierini is an extremely rare disease, It is a form of dermal atrophy and manifests as sharply demarcated hyperpigmented, non-indurated patches. These patches mark a slight depression of the skin from surrounding area with an abrupt edge.

PATHOPHYSIOLOGY: The cause of atrophoderma of pasini pierini is unknown; Borrelia burgdorferi has been suggested as the causative agent by some authors.

CLINICAL PRESENTATION: Atrophoderma is asymptomatic, begins during childhood or adolescence, congenital forms are extremely rare. It is considered as a variant of morphea by some authors.

Single lesion may be present, but more often multiple lesions are present, the lesions may be 1 to $12 \mathrm{cms}$ in diameter, lesions later become hyperpigmented, slate grey to brown in colour, discrete new lesions appear for 10 to 20 years, distribution is more commonly bilateral and symmetrical. Transformation to generalized morphea has not been observed. When skin gets depressed it gives rise to "cliff drop border". In a study described by saleh et al hypopigmented lesions were observed in about $56 \%$ of the patients. ${ }^{(8)}$ In a study $53 \%$ of 26 patients examined were found to be positive for anti B. burgdorferi immunoglobulins G. No immunoglobulin M was found.

\section{DIFFERENTIAL DIAGNOSIS:}

- Anetoderma.

- Lichen scleroses' et atrophicus.

- Morphea.

- Post inflammatory hyperpigmentation.

INVESTIGATIONS: Base line study for blood and urine, Screening test to detect anti B. Burgdorferi antibodies (ELISA). ${ }^{(9)}$ Thyroid profile must be performed because of links between cutaneous fibrosis and thyroid gland.

IMAGING STUDY: The thickness of dermis or subcutis may be measured using MRI or BB mode USG. ${ }^{(10)}$ 
SKIN BIOPSY: They are often minimal and non-diagnostic, decrease in size of dermal papillae, epidermis normal or slightly atrophic, melanin may be increased in basal cell layer. Elastic fibers appear normal after elastic tissue staining. If sclerodermatous changes are present, histology may reveal varying degree of collagen sclerosis resembling morphea.(11)

Direct immunofluorescence may show immunoglobulin $\mathrm{M}$ and C3 staining.(11)

TREATMENT AND MANAGEMENT: No treatment is consistently effective.Some patients respond to topical corticosteroids, antibiotics and antimalarials. In B.burgdorferi + patients oral penicillin 2 million IU units/D OR oral tetracycline 500mg 3 times a day for 2 to 3 weeks. A case report of improvement with doxycycline $200 \mathrm{mg}$ B.D exist.(12)

SURGICAL TREATMENT: Not been proven to be very useful. Q switched alexandrite laser $755 \mathrm{~nm}$ has been found to be effective in decreasing the hyperpigmentation by $50 \%$ after 3 treatments.

CONCLUSION: Atrophoderma of pasini pierini is a rare disease, with its congenital occurrence even rarer. Its co-occurrence with progressive vitiligo and consideration as a variant of morphea, emphasizes its auto immune etiology. No specific treatment option is still available for this rare disease.

\section{REFERENCES:}

1. Pasini A. Atrofodermia idiopatica progressiva. G Ital Dermatol. 1923; 58: 785.

2. Pierini L, Vivoli D. Atrofodermia progressiva (Pasini). G Ital Dermatol. 1936; 77: 403-09.

3. Canizares O, Sachs PM, Jaimovich L, Torres VM. Idiopathic atrophoderma of Pasini and Pierini. AMA Arch Derm. Jan 1958; 77 (1): 42-58; discussion 58-60.

4. Kim SK, Rhee Sh, Kim YC, Lee ES, Kang HY. Congenital atrophoderma of Pasini and Pierini. J Korean Med Sci. Feb 2006; 21(1):169-71. [Medline].

5. Handler MZ, Alshaiji JM, Shiman MI, Elgart GW, Schachner LA. Congenital idiopathic atrophoderma of Pasini and Pierini. Dermatol Online J. Apr 15 2012; 18 (4):

6. Miteva L, Kadurina M. Unilateral idiopathic atrophoderma of Pasini and Pierini. Int J Dermatol. Nov 2006; 45 (11): 1391-3.

7. Kopec-Medrek M, Kotulska A, Zycinska-Debska E, Widuchowska M, Kucharz EJ. Exacerbated course of atrophoderma of Pasini and Pierini in patient with papillary cancer of the thyroid gland. Wiad Lek. 2010; 63 (1): 24.

8. Saleh Z, Abbas O, Dahdah MJ, Kibbi AG, Zaynoun S, Ghosn S. Atrophoderma of Pasini and Pierini: a clinical and histopathological study. J Cutan Pathol. Dec 2008; 35 (12): 1108-14.

9. Buechner SA, Rufli T. Atrophoderma of Pasini and Pierini. Clinical and histopathologic findings and antibodies to Borrelia burgdorferi in thirty-four patients. J Am Acad Dermatol. Mar 1994; 30 (3): 441.

10. Abe I, Ochiai T, Kawamura A, Muto R, Hirano Y, Ogawa M. Progressive idiopathic atrophoderma of Pasini and Pierini: the evaluation of cutaneous atrophy by $13-\mathrm{MHz}$ B-mode ultrasound scanning method. Clin Exp Dermatol. May 2006; 31 (3): 462-4.

11. Kernohan NM, Stankler L, Sewell HF. Atrophoderma of Pasini and Pierini. An immunopathologic case study. Am J Clin Pathol. Jan 1992; 97 (1): 63-8. 


\section{CASE REPORT}

12. Lee Y, Oh Y, Ahn SY, Park HY, Choi EH. A Case of Atrophoderma of Pasini and Pierini Associated with Borrelia burgdorferi Infection Successfully Treated with Oral Doxycycline. Ann Dermatol. Aug 2011; 23 (3): 352-6.

\section{AUTHORS:}

1. Kanishk Utkarsh Kaushik

2. Anil Kumar Gupta

3. Kankambari Pandey

\section{PARTICULARS OF CONTRIBUTORS:}

1. $3^{\text {rd }}$ Year Junior Resident, Department of Dermatology, B. R. D. Medical College, Gorakhpur.

2. Assistant Professor, Department of Dermatology, B. R. D. Medical College, Gorakhpur.
3. $1^{\text {st }}$ Year Junior Resident, Department of Opthalmology, G. S. V. M. Medical College, Kanpur.

\section{NAME ADDRESS EMAIL ID OF THE CORRESPONDING AUTHOR:}

Dr. Kanishk Utkarsh Kaushik,

D. C. M, Golghar, Gorakhpur-273001, U. P.

Email: kanishk_007kaushik@yahoo.co.in

Date of Submission: 28/11/2014.

Date of Peer Review: 29/11/2014.

Date of Acceptance: 13/12/2014.

Date of Publishing: 18/12/2014. 